\title{
Induction of Peripheral Tolerance in Dual TCR T Cells: an Evidence for Non-dominant Signaling by One TCR
}

\author{
Chaerim Hah, Mihyung Kim and Kilhyoun Kim* \\ Division of Molecular Life Sciences and College of Pharmacy, Ewha Womans University, Seoul 120-750, Korea
}

Received 1 April 2004, Accepted 5 January 2005

\begin{abstract}
Recently, the existence of $T$ cells with dual $T$ cell receptor (TCR) in the immune system is generally accepted, while it has been controversial whether signals through one TCR would affect the functions of the other. In this study $T$ cells expressing two different TCR were obtained from crosshybrids of LCMV and AND TCR transgenic mice specific for the gp33 and peptide fragment of PCC (fPCC), respectively. Peptide stimulation demonstrated that the dual TCR $T$ cells functioned independently in an antigenspecific manner. To examine whether the tolerance targeted for the one TCR affects the responsiveness of the other, the cross-hybrids were treated with gp33. Although $T$ cells from $F 1$ mice were rendered anergenic to gp33, no functional changes to fPCC were observed in terms of cellular proliferation and IL-2 secretion, suggesting that the dual TCR T cells remained reactive to $f P C C$. We therefore propose that signaling through the TCR is receptor-specific and 'negative dominance' of one TCR by tolerance induction is not applicable in this dual TCR system.
\end{abstract}

Keywords: Autoimmune, Dual TCR, Synthetic peptide, TCR Transgenic mice, Tolerance

\section{Introduction}

"One T cell - one antigen receptor" has been accepted to be the general principle of $\mathrm{T}$ cell receptor (TCR) expression. Recently, however, it was found that $\mathrm{T}$ cells expressing two different TCRs are not rare, presumably due to the incomplete allelic exclusion of TCR $\alpha$ chain. This dual TCR cells were discovered to occupy up to $30 \%$ of peripheral $\mathrm{T}$ cell repertoire in rodents and humans, and became higher in their frequency

\footnotetext{
*To whom correspondence should be addressed.

Tel: 82-2-3277-2549; Fax: 82-2-3277-3051

E-mail: khyounk@ewha.ac.kr
}

as individuals grew older (Casanova et al., 1991; Padovan et al., 1993; von Boehmer, 1993; Heath et al., 1995). Therefore, they are increasingly recognized for their physiological significance in the immune system.

Dual TCR cells have been considered as a potential cause for autoimmune diseases that is involved in breaking immunological tolerance (Zal et al., 1996; Fossati et al., 1999). Immune system maintains self-tolerance, which can be achieved by both negative selection during "education" process in the thymus (Kappler et al., 1987; Kappler et al., 1988; MacDonald et al., 1988; Sha et al., 1988) and several mechanisms (Miller and Morahan, 1992; Hammering et al., 1993) such as clonal deletion (Webb et al., 1990; Rocha and von Boehmer, 1991; Moscophidis et al., 1993), anergy (Burkly et al., 1989; Rammensee et al., 1989) and ignorance (Schild et al., 1990; Ferber et al., 1994) in the periphery. Nevertheless, under some circumstances, the breakdown of self-tolerance occurs in vivo, which leads to autoimmunity (Oldstone, 1987; Ohashi et al., 1991; Röcken et al., 1992). Several hypotheses have been suggested to explain the phenomenon. Cross-reactive recognition of shared peptide sequences between pathogen and self-molecules or bystander activation that is induced by immune response to irrelevant antigens, has been proposed as a mechanism for activation of inert self-specific T cells (Oldstone, 1987; Ohashi et al., 1991; Röcken et al., 1992). Dual TCR cells could provide potent auto-reactive potential in such instances, since one of TCRs on them may not go through thymic education. According to the previous reports, dual TCR cells that have self-reactive TCR might be able to escape negative selection in the thymus and exit to periphery due to low levels of auto-specific receptor (Zal et al., 1996; Sarukhan et al., 1998). If these T cells are once activated by stimulation via the other receptor at the periphery, which could affect throughout the cellular signal transduction and lead the second auto-specific receptor to being reactive (Zal et al., 1996; Fossati et al., 1999).

Meanwhile, peptide-induced $\mathrm{T}$ cell tolerance could represent a powerful tool to treat autoimmune diseases. Several reports have demonstrated that it is possible to tolerize $\mathrm{T}$ cells in an 
antigen-specific manner by systemic application of synthetic peptides and therefore to prevent autoimmune diseases (Ferber et al., 1994; Aichele et al., 1995; Aichele et al., 1997). However, it has not yet been demonstrated whether peptidespecific tolerance could be induced in dual TCR T cells, and if so, tolerance induced on one TCR would inhibit the immune response via the other receptor.

We here obtained dual TCR T cells from cross-hybrid between AND and LCMV TCR transgenic mice. One receptor is specific for a fragment of pigeon cytochrome $\mathrm{c}$ (fPCC) bound to $\mathrm{IE}^{\mathrm{k}}$ class II MHC molecule, and the other is specific for gp33 peptide of lymphocytic choriomeningitis virus (LCMV) bound to $\mathrm{D}^{\mathrm{b}}$ class I molecule. We found that dual TCR T cells were tolerized by peptide treatment protocol and immunological tolerance induced against gp33-specific TCR on the dual TCR T cell did not impose any functional suppression to the fPCC-specific TCR in terms of proliferation and IL-2 secretion. These data suggest that the T cells in this dual TCR T cell system can differentiate signals transmitted through distinct receptors.

\section{Materials and methods}

Mice B10.A (B10.A SgSn, H-2 ${ }^{k}$ ) and LCMV TCR transgenic (C57BL/6D2-TgN(TcrLCMV)327Sdz homozygous, H-2 ${ }^{b}$ ) mice were obtained from Jackson Laboratory (Bar Harbor, USA). AND TCR transgenic mice (C57BL/10SgSnAi-[Tg]TCR-Cyt-AND N14 homozygous, $\mathrm{H}-2^{b}$ ) were crossed with the B10.A strain to observe the fPCC-specific response (see below), which were obtained from Taconic (Germanton, USA; Kaye et al., 1989). To obtain the dual TCR offsprings, AND TCR transgenic mice were crossed with LCMV TCR transgenic mice (Pircher et al., 1989). All mice were kept under the specific pathogen-free conditions.

Peptides Peptide fragment of pigeon cytochrome $\mathrm{C}$ residue 88103 (fPCC, KAERADLIAYLKQATA) and LCMV glycoprotein peptide 33-41 (gp33, KAVYNFATM) were synthesized by solidphase synthesis (Aichele et al., 1995; Aichele et al., 1997). The synthetic peptides were purified to $>90 \%$ purity by reverse-phase HPLC. To prevent dimer formation, the cysteine at the anchor position 41 in gp33 was replaced by methionine (Aichele et al., 1995; Aichele et al., 1997).

Tolerance induction and cell culture gp33 peptide $(500 \mu \mathrm{g})$ were dissolved in Hanks' balanced salt solution (HBSS, GibcoBRL, Grand Island, USA), emulsified $1: 1$ (volume/volume) in incomplete Freund's adjuvant (IFA, Sigma Chem. Co., St. Louis, USA), and injected intraperitoneally at three-day intervals in a total volume of $200 \mu \mathrm{l}$ (Kyburz et al., 1993; Aichele et al., 1995; Aichele et al., 1997). Emulsion containing IFA and HBSS was injected to mice as a control. Ten days after the final injection, the spleens or lymph nodes were removed from the mice and were generated into single cell suspensions in HBSS. After washing with HBSS, red blood cells (RBC) were lysed by incubating with RBC lysis buffer $\left(0.017 \mathrm{M}\right.$ Tris base and $\left.0.144 \mathrm{M} \mathrm{NH}_{4} \mathrm{Cl}\right)$. The resulting cells were cultured with an appropriate peptide $(10 \mu \mathrm{M})$ in a RPMI-
1640 medium (GibcoBRL) supplemented with $10 \%$ fetal bovine serum (FBS; GibcoBRL), $2 \mathrm{mM}$ L-glutamine, 10 units $/ \mathrm{mL}$ penicillin $\mathrm{G}, 100 \mu \mathrm{g} / \mathrm{mL}$ streptomycin, $250 \mathrm{ng} / \mathrm{mL}$ amphotericin $\mathrm{B}$, $10 \mathrm{mM}$ HEPES, $24 \mathrm{mM} \mathrm{Na}_{2} \mathrm{HCO}_{3}$, and $5 \times 10^{-5} \mathrm{M} 2$-mercaptoethanol.

T cell proliferation assay Cells from spleens or lymph nodes of the immune mice $\left(7 \times 10^{5}\right.$ cells $/ 200 \mu \mathrm{l} /$ well $)$ were incubated in $96-$ well flat-bottom plate with indicated amounts of peptides. Alternatively, spleen cells $\left(5 \times 10^{4}\right.$ cells) from F1 (ANDxB10.A) were used as responders to determine $\mathrm{PCC}$-specific proliferation and were incubated with mitomycin C-treated splenocytes $\left(6 \times 10^{5}\right.$ cells) from B10.A mice as stimulators. Forty-eight hours later cultures were pulsed with $0.5 \mu \mathrm{Ci} /$ well of $\left[{ }^{3} \mathrm{H}\right]$-thymidine (New England Nuclear, Du Pont, Boston, USA) for $16-20 \mathrm{~h}$ and then harvested. Radioactivity value was calculated by the mean counts per minute (cpm) of triplicate determinations determined in a liquid scintillation counter (Beckman, Palo Alto, USA). The cultures without peptide or with irrelevant peptides were used as a negative control. For positive control, suspension containing 5\% concanavalinA-activated rat spleen culture supernatant (CAS) was used.

Cytotoxicity assay Cytotoxicity was measured in a standard $4 \mathrm{~h}$ ${ }^{51} \mathrm{Cr}$-release assay. Target cells were pulsed with peptide of interest at a $10 \mu \mathrm{g} / \mathrm{ml}$ concentration for $2 \mathrm{~h}$, washed with HBSS, and labeled with $25 \mu \mathrm{Ci} / \mathrm{ml}$ of $\mathrm{Na}_{2}{ }^{51} \mathrm{CrO}_{4}(\mathrm{NEN}$, Boston, USA) for $1 \mathrm{~h}$ at $37^{\circ} \mathrm{C}$. After being washed three times with HBSS, the target cells were plated with effector cells in a microtiter assay plate at an indicated effector:target ratio (E:T) and incubated for $4 \mathrm{~h}$ at $37^{\circ} \mathrm{C}$. Radioactivity in the supernatant was then determined by g-radiation counting. The specific lysis was determined using the formula [(experimental release - spontaneous release)/(maximum release spontaneous release) $] \times 100$. All experiments were performed in triplicate and the spontaneous release was always less than $15 \%$ of the maximum release.

Interleukin-2 (IL-2) assay IL-2-starved CTLL-2 cells $\left(5 \times 10^{3}\right.$ cells/well) were incubated with supernatants obtained from $\mathrm{T}$ cells cultured for $16 \mathrm{~h}$, and then pulsed with $0.5 \mu \mathrm{Ci} /$ well of ${ }^{3} \mathrm{H}$ thymidine. After additional $12 \mathrm{~h}$ incubation, cells were harvested and processed for determination of radioactivity incorporated by liquid scintillation counting. Their radioactivity was calculated as the mean cpm of triplicate determinations. Cultures with 5\% CAS were used for positive control.

Depletion of $\mathrm{CD8}^{+} \mathbf{T}$ cells $\mathrm{CD}^{+} \mathrm{T}$ cells were depleted from splenocytes by using MiniMACS ${ }^{\circledR}$ magnetic separation system (Miltenyl, Bergisch Gladbach, Germany) according to the manufacturers instruction. Briefly, splenocytes from mice were incubated with magnetic microbeads conjugated to anti-mouse CD8 $\mathrm{mAb}$ on ice for $45 \mathrm{~min}$. After washing with MACS buffer (PBS containing $0.5 \%$ bovine serum albumin and $2 \mathrm{mM}$ EDTA), cells were applied onto the MACS separation column equipped on the magnetic field. Eluted cell suspension was used for the experiments and included less than $1 \%$ of $\mathrm{CD}^{+} \mathrm{T}$ cells when determined by a flow cytometer (Becton Dickinson, San Jose, USA).

Antibodies and flow cytometry To identify the phenotype of T 
cells from spleen or lymph node, following antibodies were used: PE-conjugated GK1.5 or Cy-chrome-conjugated GK1.5 for CD4, FITC-conjugated 53-6.7 or PE-conjugated 53-6.7 for CD8 $\alpha$, PEconjugated KJ25 for V $\beta 3$, and FITC-conjugated F23.1 for V $\beta 8$. All antibodies were purchased from PharMingen (San Diego, USA). Cells were incubated with the appropriated combinations of antibody for $30 \mathrm{~min}$ on ice with light protection and washed with cold D-PBS containing 2.5\% new-born bovine serum (NBS; GibcoBRL). Fluorescence intensity was measured with a flow cytometer.

\section{Results}

Most T cells from F1 (ANDxLCMV) mice have two TCR $\beta$ chains To obtain dual TCR T cells, we prepared crosshybrids of AND and LCMV TCR transgenic mice. Cells from peripheral lymphoid tissue and thymus of two transgenic mice were analyzed by flow cytometry to identify transgenic $\mathrm{T}$ cells (Fig. 1). AND TCR transgenic mice showed that more than $90 \%$ of peripheral $\mathrm{T}$ cells were $\mathrm{CD}^{+}$and $\mathrm{V} \beta 3^{+}$. Thymocytes also showed CD4-biased pattern and $95 \%$ of them were $\mathrm{V} \beta 3^{+}$. LCMV TCR transgenic mice displayed a strongly skewed CD8 expression in lymph node and thymus. $85 \%$ of lymph node $\mathrm{T}$ cells and thymocytes was $\mathrm{CD}^{+}$and most of the $\mathrm{CD} 8^{+}$ $\mathrm{T}$ cells were $\mathrm{V} \beta 8^{+}$. V $\beta 3$ expression on LCMV TCR T cells and V $\beta 8$ expression on AND TCR T cells were below than $1 \%$ of peripheral $\mathrm{T}$ cells (data no shown). Since parental strains were homozygous for TCR expression and the two transgenes had already been rearranged, it was expected that both TCRs would be co-expressed on the same $\mathrm{T}$ cell regardless of allelic exclusion (Borgulya et al., 1992; Blichfeldt et al., 1996). To confirm co-expression of the two TCRs, lymph node and thymus of the cross-hybrid were analyzed for TCR V $\beta$ chain and CD4/CD8 molecules (Fig. 1). Composition of $\mathrm{CD}^{+}$and $\mathrm{CD} 8^{+}$cells was similar to that of normal, non-transgenic C57BL/6 mice; $\mathrm{CD}^{+} \mathrm{T}$ cell was about $29 \%$, and $\mathrm{CD} 8^{+} \mathrm{T}$ cell was $20 \%$. As expected, most of T cells from the F1 mice were $\mathrm{V} 3^{+}$and $\mathrm{V} \beta 8^{+}$, that is, dual TCR $\mathrm{T}$ cells. While V $\beta 3$ expression level was hardly changed, there was a slight decrease of surface V $\beta 8$ expression in $\mathrm{F} 1$
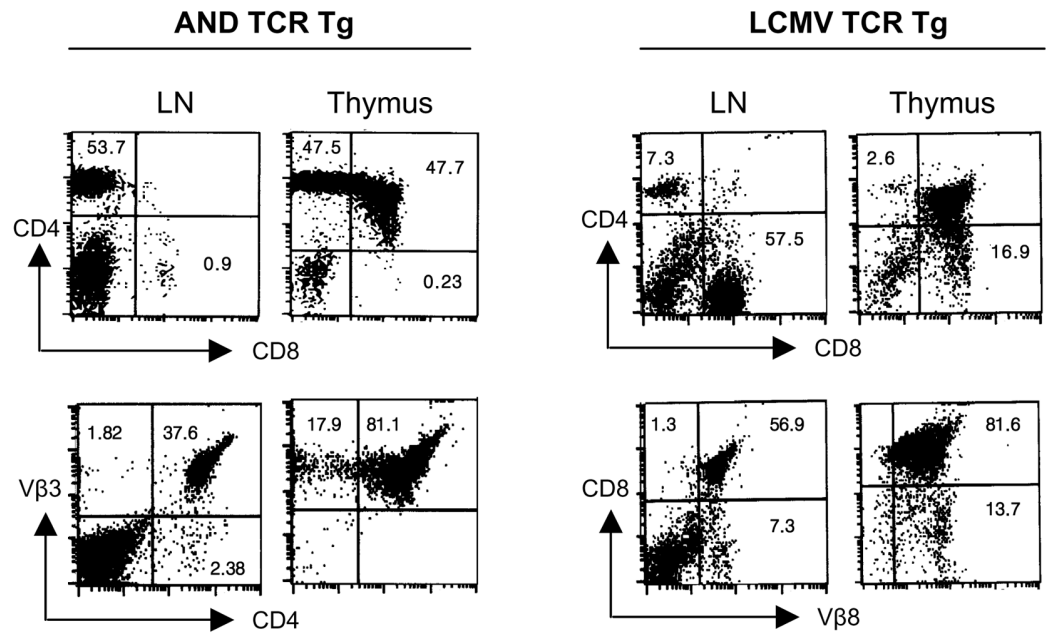

ANDXLCMV TCR Tg
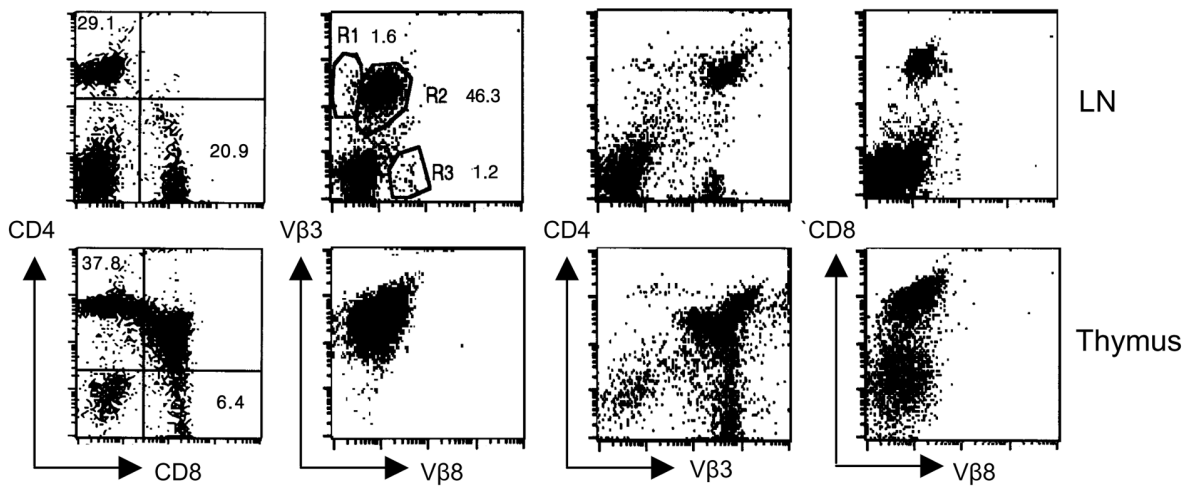

Fig. 1. Phenotypic analysis of TCR transgenic mice. Single-cell suspensions of splenocytes, lymph node cells or thymocytes were prepared from AND TCR transgenic mice, LCMV TCR transgenic mice, and F1 (AND x LCMV TCR transgenic mice). Each of cell suspension was stained with indicated mAbs and then analyzed by a flow cytometer. 
(A)

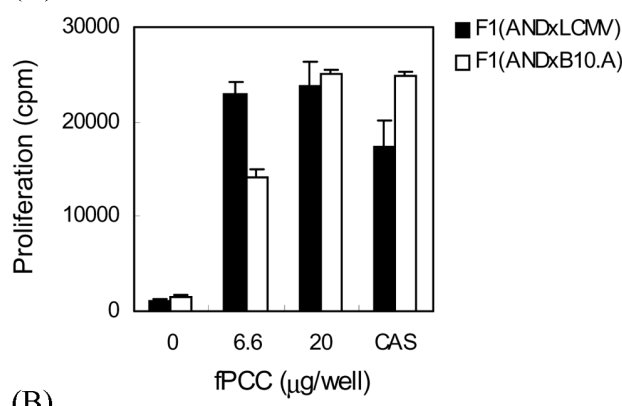

(B)

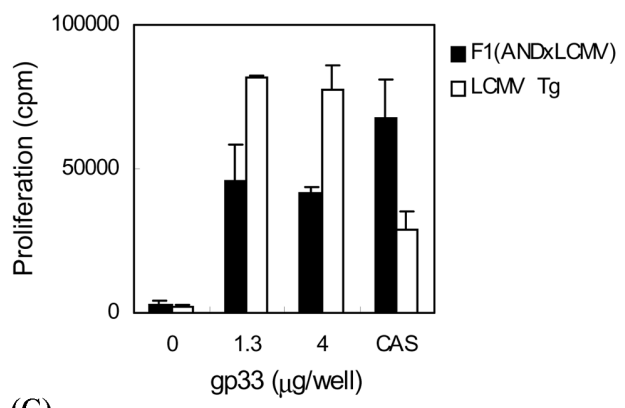

(C)

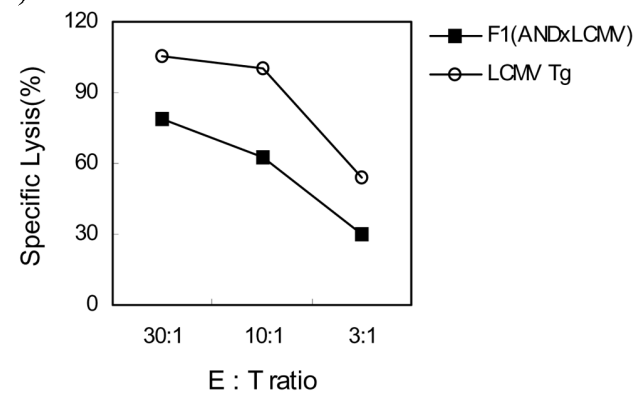

Fig. 2. Response of dual TCR T cells to $\mathrm{PPCC}$ and gp33. (A) Splenocytes from F1 (ANDxLCMV) or from F1 (ANDxB10.A) mice were cultured with the indicated amounts of PPCC for 2 days. Mytomycin C-treated B10.A splenocytes were added to the cultures as APC. Proliferation was determined by $\left[{ }^{3} \mathrm{H}\right]$-thymidine incorporation. The proliferation value (cpm) shown at the indicated antigen concentrations represent the average of triplicate experiments. (B and C) Splenocytes from F1 (ANDxLCMV) or from LCMV TCR transgenic mice were cultured with the indicated amounts of gp33 for 2 days and proliferation was determined by $\left[{ }^{3} \mathrm{H}\right]$-thymidine incorporation (upper panel). For cytotoxicity assay, splenocytes from F1 (ANDxLCMV) or from LCMV TCR transgenic mice were cultured with $10 \mu \mathrm{M}$ of gp33 for 5 days (lower panel). Cells harvested from that culture were used as an effector and incubated with gp33-pulsed EL-4 target cells for $4 \mathrm{~h}$. Untreated targets were used as a negative control and control release was always less than $15 \%$. The specific lysis values represent the average of triplicate experiments.

mice, compared with its parent, LCMV TCR transgenic mice. Although it is not clear whether LCMV TCR transgene is inferior to AND TCR transgene in competition for expression, it might result from thymic selection of moderate avidity. It has also been previously reported that each TCR expression
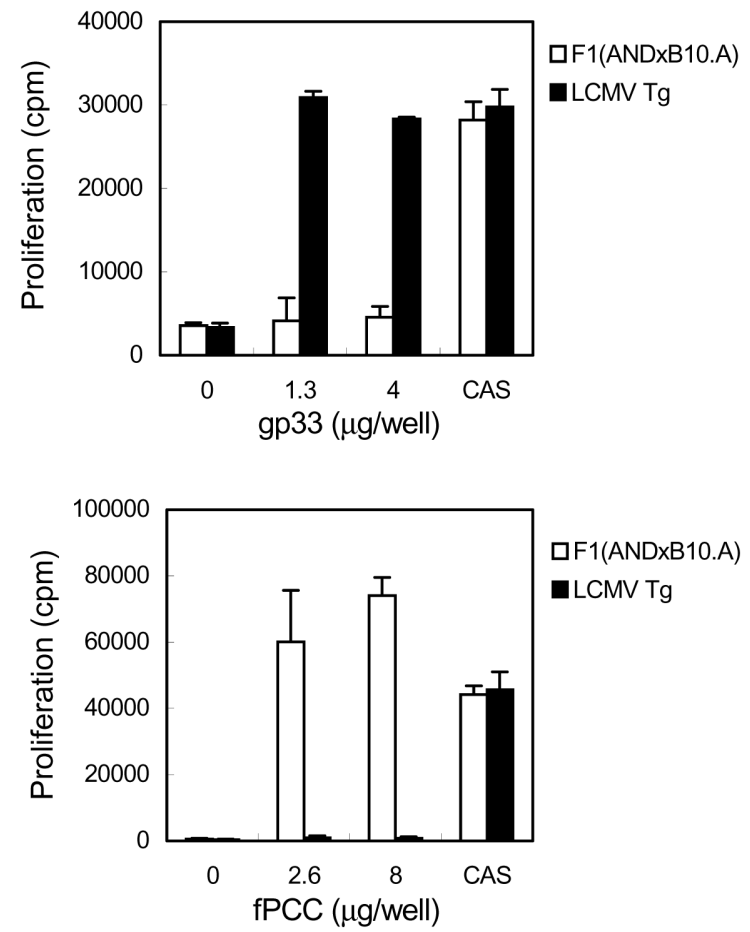

Fig. 3. Evaluation of cross-reactivity between AND TCR and LCMV TCR. Response of AND TCR to gp33 (upper panel) and LCMV TCR to fPCC (lower panel) was examined. Splenocytes from F1 (ANDxB10.A) and LCMV TCR transgenic mice were cultured with gp33 or fPCC and proliferation assay was performed as described in Fig. 2A.

level in dual TCR T cell was lower than that of single TCR T cells (Heath and Miller, 1993; George et al., 1995; Blichfeldt et al., 1996).

Dual TCR T cells are responsive to both antigens It was examined whether these dual TCR $\mathrm{T}$ cells retain their responsiveness to each of their original ligand fPCC and gp33. Splenocytes from F1 mice were assayed for proliferation in response to the $\mathrm{APCC}$ and their proliferative capacity was compared with splenocytes from AND TCR transgenic mice back-crossed with B10.A mice (Fig. 2A). Since the crosshybrid mice have $\mathrm{H}-2^{\mathrm{b}}$ background, and accordingly $\mathrm{T}$ cells from the mice cannot be stimulated appropriately by its own APCs due to absence of $\mathrm{IE}^{\mathrm{k}}$ molecules, splenocytes from B10.A mice $\left(\mathrm{H}-2^{k}\right)$ were used as APCs. As shown in Figure 2A, proliferation of the splenocytes from F1 was comparable to that from AND TCR transgenic mice, indicating that the dual TCR T cells were responsive to PPCC. In this assay, no allogenic response was observed between $\mathrm{H}-2^{\mathrm{b}}$ responder cells and $\mathrm{H}-2^{\mathrm{k}} \mathrm{APCs}$, presumably due to limited T cell repertoire of the TCR transgenic mice. When responsiveness to gp33 of F1 mice was also examined, F1 splenocytes showed gp33specific proliferation (Fig. 2B) and cytotoxic activity (Fig. $2 \mathrm{C})$. These results indicate that dual TCR T cells from crosshybrids were responsive to both PPCC and gp33. 
To exclude the possibility that two different TCRs on the dual receptor $\mathrm{T}$ cells obtained from $\mathrm{F} 1$ mice are cross-reactive to the other ligand, proliferation of each transgenic splenocytes to the other peptide was examined (Fig. 3). Neither of the T cells shows any cross-reactivity toward the other antigen. Thus, dual TCR T cells that were used in this study turned out to express two functionally-independent TCR V $\beta$ chains, V $\beta 3$ and V $\beta 8$ associated with one of the two coreceptors, CD4 or CD8.

CD8 is not required for activation of dual TCR T cells Although $\mathrm{T}$ cells from cross-hybrids were immunocompetent for both antigens, responsiveness to gp33 was a little decreased, compared to T cells from LCMV TCR transgenic mice (Fig. 2B). On the contrary, proliferation induced by fPCC was not significantly different between single TCR T cells and dual TCR T cells. Reduced responsiveness to gp33 might be due to reduced TCR V $\beta 8$ expression. This is consistent with the previous study that dual TCR T cells showed reduced sensitivity to their ligands due to decreased receptor density (Blichfeldt et al., 1996).

However, considering that the $\mathrm{T}$ cell coreceptor, CD4 or CD8 plays a critical role for development and activation of most T cells (Racioppi et al., 1996; von Boehmer and Kisielow, 1998; Robertson and Evavold, 1999) and that most dual TCR T cells express either CD4 or CD8 in this dual TCR transgenic mice, it is possible that the reduced responsiveness of the dual TCR T cells might be due to unavailability of appropriate coreceptor in the $\mathrm{T}$ cell response to gp33. To examine this possibility, $\mathrm{CD}^{+}$dual TCR $\mathrm{T}$ cells were prepared and responsiveness to an MHC class I-restricted antigen gp33 was measured. By using the magnetic separation column packed with anti-CD8 microbeads, $\mathrm{CD} 8^{+} \mathrm{T}$ cells were removed from the eluted cell suspension. The resulting cell population included less than $1 \%$ of $\mathrm{CD}^{+} \mathrm{T}$ cell (data not shown). When $\mathrm{CD}^{+}$dual TCR $\mathrm{T}$ cells were examined for proliferation, they proliferated in response to gp33 as highly as non-depleted whole splenocytes (Fig. 4). Thus, CD8 did not seem to be required to activate LCMV TCR T cells. Hence, dual TCR T cells in this system seem to have bifunctional reactivity, at least on the gp33-specific response, regardless of their coreceptor expression.

Dual TCR $T$ cells were tolerized by overdosed antigen Repetitive systemic antigen administration has been well established to induce tolerance (Kyburz et al., 1993; Aichele et al., 1995; Aichele et al., 1997). An overdose of antigen was treated to LCMV TCR transgenic mice and F1 mice in order to examine whether dual TCR T cells are also tolerized by peptide administration. gp33 peptide dissolved in IFA was given to peritoneal cavity three times at 3-day intervals. Tolerance by this protocol was known to last for three weeks after final antigen injection in non-thymectomized LCMV TCR transgenic mice (Aichele et al., 1995). After peptide administration, LCMV TCR transgenic mice were tested for

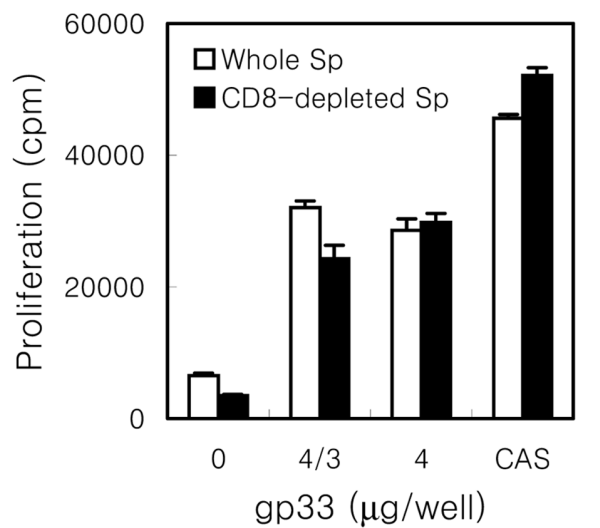

Fig. 4. Response of $\mathrm{CD}^{+}$dual $\mathrm{TCR} \mathrm{T}$ cells to gp33. $\mathrm{CD}^{+} \mathrm{T}$ cells were removed from whole splenocytes of F1 (ANDxLCMV) mice as described in Materials and Methods. CD8-depleted cells and whole splenocytes of F1 were stimulated with indicated concentrations of gp33 and proliferation assay was performed as described in Fig. 2B. The data represent one of three independent experiments.

proliferation and CTL activity to confirm the tolerance obtained by this protocol (Fig. 5A). Consistent with the previous results (Kyburz et al., 1993; Aichele et al., 1995), LCMV TCR T cells in this study were not responsive to gp33. When the same protocol of antigenic challenge was applied to the F1 mice with dual TCR T cells, no significant proliferation and CTL activity, as in parental LCMV TCR transgenic mice, were observed. This result indicates that dual TCR T cells were tolerized totally in response to gp33 and tolerance induction by soluble peptide was applicable in this dual TCR $\mathrm{T}$ cell system. This tolerance presumably reflects anergy rather than clonal deletion, because the number of $\mathrm{CD}^{+} \mathrm{V} \beta 8^{+}$ $\mathrm{T}$ cells changed little after tolerance induction (Fig. 5B) and the total number of $\mathrm{V} \beta 8^{+} \mathrm{T}$ cells also did not show significant reduction (data not shown). If deletion had occurred at all, it would have been biased to $\mathrm{V} \beta 8^{\text {hi }}$ population. However, it is not clear that this might reflect a down-regulation of TCR, which is also a non-deletional tolerance mechanism (von Boehmer and Kisielow, 1998).

Dual TCR T cells may differentiate signals transmitted through distinct receptors The dual TCR T cells were examined whether immunological tolerance induced through one TCR would affect functions of the other. F1 mice that had been treated with an overdose of gp33 were evaluated for responsiveness to fPCC. Although the dual TCR T cells from $\mathrm{F} 1$ mice were rendered tolerant for gp33 as shown in Fig 5A, they still remained responsive to fPCC (Fig. 6). They proliferated for APCC as strongly as T cells from IFA-treated F1 mice. IL-2 secretion was also comparable to that of nontolerized F1 mice.

Because the proportions of $\mathrm{V} \beta 3^{+} \mathrm{T}$ cells and of $\mathrm{CD}^{+} \mathrm{T}$ cells were not changed significantly after tolerance induction 
(A)

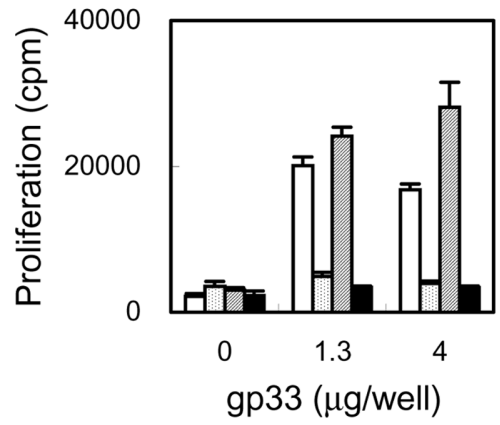

(B)

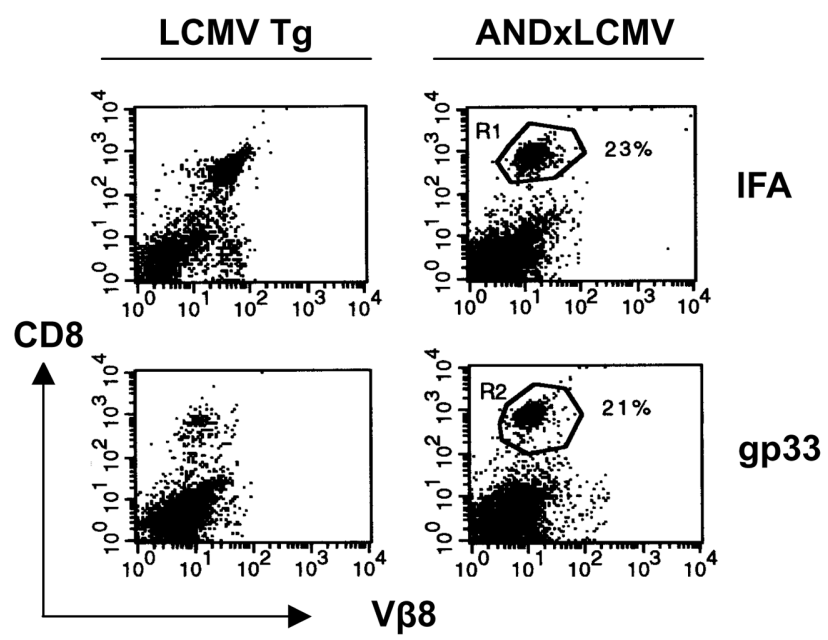

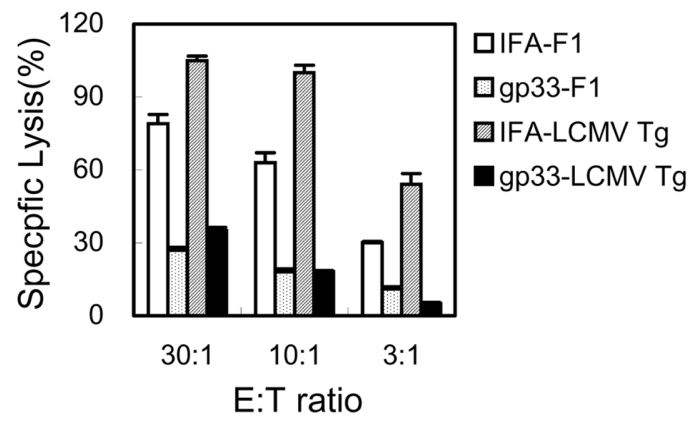

\section{A}

33

Fig. 5. Tolerance induction and identification of dual TCR T cells responsive to gp33. LCMV Tg and F1 (ANDxLCMV) were injected with $500 \mu \mathrm{g}$ of gp33 emulsified in IFA, or with IFA emulsion without gp33 intraperitoneally, three times at 3-day intervals. Splenocytes were harvested 10 days after the final injection. (A) Proliferation (left panel) and CTL activity (right panel) for gp33 were determined as described in Fig. 2B. (B) Expression of TCR and CD4/CD8 was analyzed by flow cytometry. Splenocytes from IFA-treated (upper panel) or gp33-treated (lower panel) mice were subjected to triple color staining with mAb specific for CD4, CD8 and V $\beta 8$.

(data not shown), this bi-modal response was not likely to be due to selective accumulation of $\mathrm{V} \beta 3^{+} \mathrm{T}$ cells that avoided tolerance. Therefore, these data suggest that $\mathrm{T}$ cells are able to differentiate signals delivered through distinct receptors, and tolerance imposed via one TCR does not suppress signal transduction through the other one in this dual TCR T cell system.

\section{Discussion}

Dual TCR T cells are increasingly recognized for their autoreactive potential as well as considerable frequency of occurrence in the normal $\mathrm{T}$ cell repertoire. Immunological tolerance can be achieved primarily by thymic education process. However, the occurrence of dual TCR T cells in the periphery raises the possibility that the dual TCR T cells may be able to elicit self-specific immune response, as one of dual TCRs on them did not have gone through negative selection. Previous studies focused on whether the nonselected TCR would respond to the antigens presented by self-MHC molecules and dual TCR T cells could virtually be involved in autoimmunity. Evidences for potential involvement of such $T$ cells in autoimmune diseases were provided in several TCR transgenic mouse models (Zal et al., 1996; Sarukhan et al., 1998). However, it has not yet been studied in the light of that whether immunological tolerance could be induced on dual TCR T cells having dual antigen specificity and the tolerance induced by one TCR could inhibit responses triggered by the other TCR.

In the present study, cross-hybrid mice were generated between AND and LCMV TCR transgenic mice to obtain dual TCR T cells. More than $90 \%$ of $\mathrm{T}$ cells from the littermates expressed two different TCR V $\beta$ chains that were originated from the two parental transgenic lines. Expression level of $\mathrm{V} \beta 3$, from AND TCR transgenic mice, was not changed significantly, yet that of $\mathrm{V} \beta 8$, from the other parent, was slightly reduced on the dual TCR T cells. It is not certain why expression of V $\beta 8$ was reduced. It has been reported that dual TCR T cells showed decreased surface expression of either receptor, which lead to low avidity of T cell recognition in the thymus and hence enabled such cells to escape thymic 
(A)

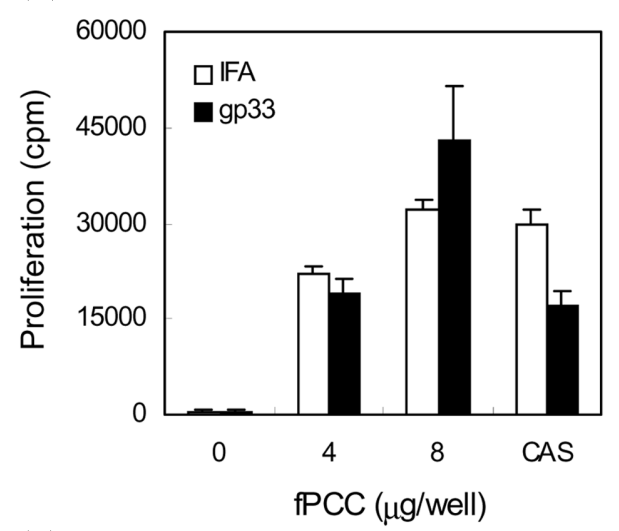

(B)

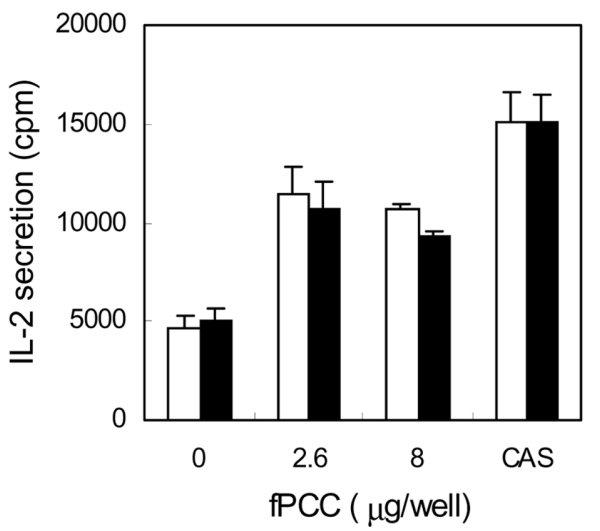

Fig. 6. Functional evaluation of gp33-anergic $\mathrm{T}$ cells for $\mathrm{fPCC}$. F1 mice were treated with gp33 or IFA as described in Fig. 4. Splenocytes from the mice were cultured with $\mathrm{PCC}$ in the presence of mitomycin C-treated B10.A splenocytes. (A) Proliferation assay was performed as described in Fig. 2A. (B) For IL-2 assay, culture supernatants were collected in $16 \mathrm{~h}$, transferred into CTLL-2 cell suspension $\left(5 \times 10^{3}\right.$ cells/well $)$, and added with $\left[{ }^{3} \mathrm{H}\right]$-thymidine. After additional $12 \mathrm{~h}$ incubation, cells were harvested and $\left[{ }^{3} \mathrm{H}\right]$-incorporation was determined. The data represent one of three independent experiments.

deletion even though they are self reactive (Heath and Miller, 1993; George et al., 1995; Blichfeldt et al., 1996). Therefore, the reduced density of TCR might be responsible for the reduced sensitivity of dual TCR $\mathrm{T}$ cells to gp33 when compared to its parental transgenic $\mathrm{T}$ cells. The dual TCR T cells from F1 mice showed antigen-specific dual specificities without cross-reactive responsiveness, providing a dual TCR $\mathrm{T}$ cell system relevant for studying signals transmitted via two TCRs.

Peptide induced tolerance induction has been considered as a representative therapeutic strategy for immunological intervention of autoimmune diseases. Previous studies demonstrated that $\mathrm{T}$ cell-mediated autoimmune diseases could be successfully prevented by tolerance induction with peptide treatment (Aichele et al., 1995; Aichele et al., 1997; Ferber et al., 1999). This prompted us to examine whether this strategy could also be applicable in the dual TCR T cell system. LCMV TCR-specific tolerance was successfully induced in F1 mice in this study by peptide administration protocol that was previously established in C57BL/6 mice (Kyburz et al., 1993; Aichele et al., 1995). After systemic and repetitive peptide administration, the F1 mice became tolerant to gp33specific response. This result indicates that dual TCR T cells could be efficiently tolerized in antigen-specific manner. In addition, MHC class I-restricted TCR signaling via V $\beta 8$ TCR did not require the CD8 coreceptor. Therefore, it is very likely that tolerance has been induced in all dual TCR T cells regardless of coreceptor association with CD4 or CD8. However, tolerance induction for fPCC-specific TCR could not be performed in F1 mice because of a systematic drawback. Since fPCC is presented by $\mathrm{IE}^{\mathrm{k}}$ molecule to TCR (V $\alpha 11, \mathrm{~V} \beta 3$ ), fPCC recognition restricted by $\mathrm{IE}^{\mathrm{k}}$ was not expected to occur in these F1 mice with $\mathrm{H}-2^{\mathrm{b}}$ background.

Meanwhile, in this dual TCR system, one TCR-specific tolerance did not seem to suppress immune responses mediated by the second TCR, since dual TCR T cells was still responsive to $\mathrm{APCC}$ after rendered unresponsive to gp33, suggesting that the two receptors were functionally independent on each other. However, some reports argued that two TCRs on the same T cells were functionally dependent on each other. While addressing TCR antagonism by altered peptide ligands (APL) in dual TCR T cell systems, they showed that if the negative signaling delivered by one TCRspecific antagonist dominate, responses of the second receptor which would otherwise be normally functional could also be inhibited (Dittel et al. 1999; Racioppi et al., 1996; Roberston and Evavold, 1999). However, the negative dominance effect is variable depending on experimental systems (Racioppi et al., 1996; Daniels et al., 1999, Dittel et al., 1999; Robertson and Evavold, 1999; Stotz et al., 1999), and furthermore, a recent report (Zal et al., 2002) that TCR-coreceptor interaction in the immunological synapse was inhibited by antagonist ligands suggested that the mechanism of TCR antagonism is involved in a 'receptor competition model' rather than in the 'negative dominance model'. The present study that the negative dominance imposed by tolerance induction to one TCR is not applicable in dual TCR T cells would also be an additional evidence for the 'receptor competition model', or more appropriately, 'non-dominance model'.

Acknowledgment This work was supported by The Korea Research Foundation Grant (KRF-2003-015-C00509).

\section{References}

Aichele, P., Brduscha-Reim, K., Oehen, S., Odermatt, B., Zinkernagel, R. M., Hengartner, H. and Pircher, H. (1995) Brief definitive report: $\mathrm{T}$ cell priming versus $\mathrm{T}$ cell tolerance induced by synthetic peptides. J. Exp. Med. 182, 261-266. 
Aichele, P., Brduscha-Reim, K., Oehen, S., Odermatt, B., Zinkernagel, R. M., Hengartner, H. and Pircher, H. (1997) Peptide antigen treatment of naïve and virus-immune mice: antigen-specific tolerance versus immunopathology. Immunity 6, 519-529.

Blichfeldt, E., Munthe, L. A., Rotnes, J. S. and Bogen, B. (1996) Dual $\mathrm{T}$ cell receptor $\mathrm{T}$ cells have a decreased sensitivity to physiological ligands due to reduced density of each $\mathrm{T}$ cell receptor. Eur. J. Immunol. 26, 2876-2884.

von Boehmer, H. (1993) Developmental biology of T cells in $\mathrm{T}$ cell receptor transgenic mice. Ann. Rev. Immunol. 8, 531-556.

von Boehmer, H. and Kisielow, P. (1998) Self-nonself discrimination by T cells. Science 248, 1369-1373.

Borgulya, P., Kishi, H., Uematsu, Y. and von Boehmer, H. (1992) Exclusion and inclusion of and $\mathrm{T}$ cell receptor alleles. Cell $\mathbf{6 9}$, 529-537.

Burkly, L. C., Lo, D., Kangawa, O., Brinster, R. L. and Flavall, R. A. (1989) T-cell tolerance by clonal anergy in transgenic mice with nonlymphoid expression of MHC II I-E. Nature 342, 564566.

Casanova, I. L., Romero, P., Widmann, C., Kourilsky, P. and Maryanski, J. L. (1991) T cell receptor genes in a series of class I major histocompatibility complex-restricted cytotoxic $\mathrm{T}$ lymphocyte clones specific for a Plasmodium berghei nonapeptide: implication for $\mathrm{T}$ cell allelic exclusion and antigen-specific repertoire. J. Exp. Med. 174, 1371-1383.

Daniels, M. A., Schober, S. L., Hogquist, K. A. and Jameson, S. C. (1999) Cutting edge: a test of the dominant negative signal model for TCR antagonism. J. Immunol. 163, 1750-1754.

Dittel, B. N., Stefanova, I. and Germaim, R. N. (1999) Crossantagonism of a $\mathrm{T}$ cell clone expressing two distinct $\mathrm{T}$ cell receptors. Immunity 11, 289-298.

Ferber, I., Schonrich, G., Schenkel, J., Mellor, A. L., Hammerling, G. J. and Arnold, B. (1994) Levels of peripheral T-cell tolerance induced by different doses of tolerogen. Science 263, 674-676.

Fossati, G., Cooke, A., Papafio, R. Q., Haskins, K. and Stokinger, B. (1999) Triggering a second $\mathrm{T}$ cell receptor on diabetogenic $\mathrm{T}$ cells can prevent induction of diabetes. J. Exp. Med. 190, 577-583.

George, Y. L., Fairchild, P. J., Smith, R. M., Prowle, J. R., Kioussis, D. and Wraith, D. C. (1995) Low avidity recognition of self-antigen by $\mathrm{T}$ cells permits escape from central tolerance. Immunity 3, 407-415.

Hammering, G. J., Schonrich, G., Ferber, I. and Arnold, B. (1993) Peripheral tolerance as a multistep mechanism. Immunol. Rev. 133, 93-104.

Heath, W. R. and Miller, J. F. A. P. (1993) Expression of two alpha chains on the surface of $\mathrm{T}$ cells in $\mathrm{T}$ cell receptor transgenic mice. J. Exp. Med. 178, 1807-1811.

Heath, W. R., Carbone, F. R., Bertolino, P., Kelly, J., Cose, S. and Miller, J. F. A. P. (1995) Expression of two T cell receptor a chains on the surface of normal murine $\mathrm{T}$ cells. Eur. $J$. Immunol. 25, 1617-1623.

Janeway, C. A. (1992) The T cell receptor as a multicomponent signaling machine: $\mathrm{CD} 4 / \mathrm{CD} 8$ coreceptors and $\mathrm{CD} 45$ in $\mathrm{T}$ cell activation. Annu. Rev. Immunol. 10, 645-674.

Kappler, J. W., Roehm, N. and Marrack, P. (1987) T cell tolerance by clonal elimination in the thymus. Cell 49, 273-280.

Kappler, J. W., Staerz, U. D., White, J. and Marrack, P. (1988)
Self tolerance eliminates $\mathrm{T}$ cells specific for Mls-modified products of the major histocompatibility complex. Nature 332, 35-40.

Kaye, J., Hsu, M., Sauron, M., Jameson, S. C., Gascoigne, N. R. J. and Hedrick, S. M. (1989) Selective development of CD4 ${ }^{+}$T cells in transgenic mice expressing a class II MHC-restricted antigen receptor. Nature 341, 746-749.

Kyburz, D., Aichele, P., Speiser, D. E., Hengartner, H., Zinkernagel, R. M. and Pircher, H. (1993) T cell immunity after a viral infection versus $\mathrm{T}$ cell tolerance induced by soluble viral peptide. Eur. J. Immunol. 23, 1956-1962.

MacDonald, H. R., Schineider, R., Lees, R. K., Howe, R. C., Acha-Orbea, H., Festenstein, H., Zinkernagel, R. M. and Hengartner, H. (1988) T cell receptor V $\beta$ use predicts reactivity and tolerance to Misa-encoded antigens. Nature 332, 40-45.

Miller, J. F. A. P. and Morahan, G. (1992) Peripheral T Cell Tolerance. Annu. Rev. Immunol. 10, 51-69.

Moscophidis, D., Lechner, F., Pircher, H. P. and Zinkernagel, R. M. (1993) Virus persistence in acutely infected immunocompetent mice by exhausting of antiviral cytotoxic effector T cells. Nature 362, 758-761.

Ohashi, P. S., Oehen, S., Buerki, K., Pirdher, H., Ohashi, C. T., Odermatt, B., Malissen, B., Zinkernagel, R. M. and Hengartner, H. (1991) Ablation of "tolerance" and induction of diabetes by virus infection in viral antigen transgenic mice. Cell $\mathbf{6 5}, 305-$ 317.

Oldstone, M. B. (1987) Molecular mimicry and autoimmune disease. Cell 50, 819-820.

Padovan, E., Casorati, G., Dellabona, P., Meyer, S., Brockhaus, M. and Lanzavecchia, A. (1993) Expression of two T cell receptor a chains: dual receptor T cells. Science 262, 422-424.

Pircher, H., Burki, K., Lang, R., Hengartner, H. and Zinkernagel, R. M. (1989) Tolerance induction in double specific T-cell receptor transgenic mice varies with antigen. Nature 342, 559561.

Racioppi, L., Matarese, G., Doro, U., Pascale, M., Masci, A. M., Fontana, S. and Zappacosta, S. (1996) The role of CD4-Lck in T-cell receptor antagonism: evidence for negative signaling. Proc. Natl. Acad. Sci. USA 93, 10360-10365.

Rammensee, H. G., Krosschewski, R. and Frangoulis, B. (1989)

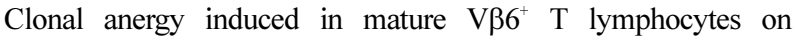
immunizing Mis-1 mice with Mis-1 expression cells. Nature 339, 541-544.

Robertson, J. M. and Evavold, B. D. (1999) Cutting edge: dueling TCRs: peptide antagonism of $\mathrm{CD}^{+} \mathrm{T}$ cells with dual antigen specificities. J. Immunol. 63, 1750-1754.

Rocha, B. and von Boehmer, H. (1991) Peripheral selection of the T cell repertoire. Science 251, 1225-1228.

Röcken, M., Urban, J. F. and Shevach, E. M. (1992) Infection breaks T-cell tolerance. Nature 359, 79-82.

Sarukhan, A., Garcia, C., Lanoue, A. and von Boehmer, H. (1998) Allelic inclusion of $\mathrm{T}$ cell receptor agenes poses an autoimmune hazard due to low-level expression of autospecific receptors. Immunity 8, 563-570.

Schild, H. J., Rotzschje, O., Kalbacher, H. and Rammensee, H. G. (1990) Limit of T cell tolerance to self-proteins by peptide presentation. Science 247, 1587-1589.

Sha, W. C., Nelson, C. A., Newberry, R. D., Kranz, D. M., Russell, J. H. and Loh, D. Y. (1988) Positive and negative selection of an antigen receptor on $\mathrm{T}$ cells transgenic mice. 
Nature 1336, 73-76.

Stotz, S. H., Bolliger, L., Carbone, F. R. and Palmer, E. (1999) T cell receptor (TCR) antagonism without a negative signal: evidence from $\mathrm{T}$ cell hybridomas expressing two independent TCRs. J. Exp. Med. 189, 253-263.

Webb, S., Morris, C. and Sprent, J. (1990) Extrathymic tolerance of mature cells: clonal elimination as a consequence of immunity. Cell 63, 1249-56.
Zal, T., Weiss, S., Mellor, A. and Stockinger, B. (1996) Expression of a second receptor rescues self-specific $\mathrm{T}$ cells from thymic deletion and allows activation of autoreactive effector function. Proc. Natl. Acad. Sci. USA 93, 9102-9107.

Zal, T., Zal, M. A. and Gascoigne, N. R. J. (2002) Inhibition of T cell receptor-coreceptor interactions by antagonist ligands visualized by live FRET imaging of the T-hybridoma immunological synapse. Immunity 16, 521-534. 